\title{
Gait analysis in patients with chronic obstructive pulmonary disease: A systematic review
}

\author{
Matteo Zago a, b, c, *, Chiarella Sforza ${ }^{\text {b, d }}$, Daniela Rita Bonardie, Enrico Eugenio Guffanti ${ }^{\mathrm{e}}$, Manuela Galli ${ }^{\mathrm{a}, \mathrm{f}}$ \\ ${ }^{a}$ Department of Electronics, Information and Bioengineering (DEIB), Politecnico di Milano, Piazza Leonardo da Vinci 32, 20133, Milano, Italy \\ ${ }^{\mathrm{b}}$ Department of Biomedical Sciences for Health, Università degli Studi di Milano, via Mangiagalli 31, 20133, Milano, Italy \\ ${ }^{\text {c }}$ Fondazione Istituto Farmacologico Filippo Serpero, Viale Luigi Majno 40, 20122, Milano, Italy \\ ${ }^{\mathrm{d}}$ Institute of Molecular Bioimaging and Physiology, National Research Council, Segrate, Italy \\ e Istituto Nazionale di Riposo e Cura per Anziani IRCCS CASATENOVO, Via Monteregio 13, 23880 Casatenovo, Lecco, Italy \\ ${ }^{\mathrm{f}}$ IRCCS San Raffaele Pisana, Roma, Italy
}

\section{A R T I C L E I N F O}

\section{Keywords:}

Gait kinematics

Locomotion

Pulmonary disease

Review

Functional assessment

Exercise capacity

\begin{abstract}
A B S T R A C T
Background: Gait instability is a major fall-risk factor in patients with chronic obstructive pulmonary disease (COPD). Clinical gait analysis is a reliable tool to predict fall onsets. However, controversy still exists on gait impairments associated with COPD.

Research question: Thus, the aims of this review were to evaluate the current understanding of spatiotemporal, kinematic and kinetic gait features in patients with COPD.

Methods: In line with PRISMA guidelines, a systematic literature search was performed throughout Web of Science, PubMed Medline, Scopus, PEDro and Scielo databases. We considered observational cross-sectional studies evaluating gait features in patients with COPD as their primary outcome. Risk of bias and applicability of these papers were assessed according to the QUADAS-2 tool.

Results: Seven articles, cross-sectional studies published from 2011 to 2017, met the inclusion criteria. Sample size of patients with COPD ranged 14-196 (mean age range: 64-75 years). The main reported gait abnormalities were reduced step length and cadence, and altered variability of spatiotemporal parameters. Only subtle biomechanical changes were reported at the ankle level.

Significance: A convincing mechanistic link between such gait impairments and falls in patients with COPD is still lacking. The paucity of studies, small sample sizes, gender and disease status pooling were the main risk of biases affecting the results uncertainty. Two research directions emerged: stricter cohorts characterization in terms of COPD phenotype and longitudinal studies. Quantitative assessment of gait would identify abnormalities and sensorimotor postural deficiencies that in turn may lead to better falling prevention strategies in COPD.
\end{abstract}

\section{Introduction}

Chronic obstructive pulmonary disease (COPD) causes over three million deaths annually, with a global prevalence of 8-15\% [1]. COPD is a lungs disease characterized by chronic airflow obstruction due to structural abnormalities of the airways (bronchitis and bronchiolitis), associated with an inflammatory reaction of the alveoli and pulmonary vessels [2]. Treatment of COPD has traditionally focused on lung function. The Global Initiative for Chronic Obstructive Lung Disease (GOLD) classifies patients according to the value of expired volume in
$1 \mathrm{~s}$ (Forced Expiratory Volume in $1 \mathrm{~s}$ or FEV1). According to GOLD, stage 1 corresponds to FEV $1 \geq 80 \%$ of predicted; stage $250 \% \leq \mathrm{FEV} 1<80 \%$ of predicted; stage $330 \% \leq \mathrm{FEV} 1<50 \%$ of predicted; stage 4 , FEV1 $<30 \%$ of predicted, while the FEV1/FVC (Forced Vital Capacity) ratio is $<70 \%$ in all stages [3]. However, COPD is also accompanied by several extrapulmonary chronic alterations that affect body systems, including weight loss, cardiovascular disease, metabolic disturbances, muscles weakness and atrophy, osteoporosis [4,5]. These persistent illnesses result in a multimorbidity condition that significantly impairs patients' health increasing the effect of common risk factors like smoking, diet, alcohol, physical inactivity and aging [3].

\footnotetext{
* Corresponding author at: Department of Electronics, Information and Bioengineering (DEIB), Politecnico di Milano, Piazza Leonardo da Vinci 32, 20133, Milano, Italy.

Email addresses: matteo2.zago@polimi.it (M. Zago); chiarella.sforza@unimi.it (C. Sforza); d.bonardi@inrca.it (D.R. Bonardi); e.guffanti@inrca.it (E.E. Guffanti); manuela.galli@polimi. it (M. Galli)
} 
In particular, as skeletal muscle weakness leads to limited mobility, motor incoordination and functional limitations, individuals with COPD present postural control impairment with respect to age-matched healthy controls [6-9]. As a consequence of such balance deficits, patients with COPD fall frequently [10-13]. This is a major health concern, since falling represents one of the main causes of pain, inactivity, disability, loss of functional independence and death in the elderly [14]. Falls induce a downward spiral of worsening frailty and loss of mobility [15]. Despite the causes of falls are multifactorial, the majority of them happen during walking [16]. A poor gait function is therefore one of the main risk of falls and a strong risk factor of death [17]. COPD may negatively impact on gait as systemic complications affect the cardiovascular and musculoskeletal system.

Gait tests like the 6-min walking test (6MWT) or the shuttle walk test are commonly adopted in clinical practice to evaluate functional performance and status $[3,18]$. These tests are simple, inexpensive and clinically relevant screening tools to assess patients with COPD for exercise capacity. Gait speed also reflects global well-being, captures multisystemic effects of disease severity [19], it is related to the risk of hospitalisation and can be used to predict survival [20].

Although walking tests and gait speed measure the overall functional status of the patients, they cannot provide information about the gait patterns, nor on the biomechanical effects of impaired postural control during gait. Gait changes are often too subtle to be detected only by clinical observations, and clinical gait analysis may be the best tool to predict fall onsets [12]. Thus, the assessment of kinematic and kinetic gait parameters enables to detect and qualify specific abnormalities and sudden sensorimotor postural deficiencies in patients with COPD, and in turn can contribute to prevent the consequences of falls [7].

To date, no systematic review has summarised the literature regarding quantitative gait abnormalities in patients with COPD. Thus, the purposes of this study are: (i) to evaluate the current understanding of spatiotemporal, kinematic and kinetic gait features in patients with COPD, and (ii) to identify relevant gaps in the actual body of knowledge.

\section{Methods}

\subsection{Search strategy}

A systematic literature search was undertaken in September 2017 on the following electronic databases: Web of Science (from 1985), PubMed MEDLINE (from 1985), Scopus (no time limit), Mendeley (from 1990), PEDro (from 1985), Scielo (no time limit). Customised queries including the following keywords and Boolean logic with AND/OR operators were entered in the search engines: "COPD", "chronic obstructive pulmonary disease", ("gait" OR "gait analysis" OR "locomotion"). The search was limited to full original articles written in English. Bibliographies of identified papers and relevant conference proceedings were hand searched for supplemental relevant items, as well as Authors' personal collection.

\subsection{Eligibility criteria and study selection}

Observational cross-sectional studies involving patients clinically diagnosed with COPD were included. We considered any functional evaluation regarding the assessment of gait mechanics in patients with COPD, including (but not restricted to) 6MWT and walking trials. Papers were included that evaluated gait features in patients with COPD as their primary outcome, in terms of spatiotemporal, kinematics and/ or kinetic parameters. Case series, i.e. studies neither analysing a con- trol group nor referring to a matched healthy population, were not included. Studies without diagnostic criteria for COPD, or based solely on walking distance/speed or qualitative assessment, plethysmography, electromyography, activity monitors or questionnaires were also excluded.

By applying these inclusion and exclusion criteria, two reviewers (DB and MZ) independently screened titles and abstracts of the identified records and took decision about items retention in a blinded manner. Any disagreement between the examiners was resolved by a technical discussion involving a third reviewer (MG).

\subsection{Evaluation of the quality of the included studies}

A standardised data extraction and appraisal form was constructed to collect the key features of each study. In particular, before the evaluation of the methodological quality of the included studies, information about authors/year, study design, participants' demographics (sex, mean age and SD) and disease status (mean and SD of FEV1/FVC) were collected.

Quality themes and principles relevant to the topic were evaluated according to the QUADAS-2 (Quality Assessment of Diagnostic Accuracy Studies, revised) tool [21]: four domains (patient selection, index test, reference standard, flow and timing) were assessed in terms of risk of bias and concerns regarding applicability. Although such tool is primarily focused upon studies of healthcare intervention, in particular randomized control trials, we adapted QUADAS-2 requirements to fit the specificity of observational cross-sectional studies conducted in gait laboratories.

\section{Results}

\subsection{Electronic literature search results}

A total of 1169 records were retrieved from the electronic databases. Eleven additional items were found through screening of reference lists and review articles, and two belonged to the Authors' personal collection. After removing 225 duplicates, titles and abstracts screening led to exclude 896 papers and conference proceedings. Despite among the latter two potentially relevant studies were identified, they were preliminary studies anticipating full-papers of the same group [22,23]. Of the remaining 61 articles, 54 were removed since they did not meet inclusion criteria. Most of them compared the outcomes of 6MWT or 4MWT (walking distance or speed) to clinical or physiological measures. Seven papers were included in the review. The selection process is summarised in Fig. 1.

\subsection{Description of the included studies}

All the included papers were observational cross-sectional studies published from 2011 to 2017 and assessing a cohort of patients with COPD and a control group, with the exception of [24], who compared their results to a previously published normative database (Table 1). The sample size of patients with COPD ranged from 14 to 196 (mean age range: 64-75 years). Three papers [22,23,25] relied on traditional optical motion capture combined with force platforms to collect full-body three-dimensional kinematics and kinetics (joint angles, moments and powers); in the remaining papers, spatiotemporal parameters and dependent variables were obtained by means of electronic walkways [12,26], video analysis [24] or inertial units [27]. All studies required participants to walk at their self-selected walking speed, either over ground (6MWT) or on a treadmill. Only Yentes et al. (2017) analysed two walking conditions at $\pm 20 \%$ of self-selected speed. 


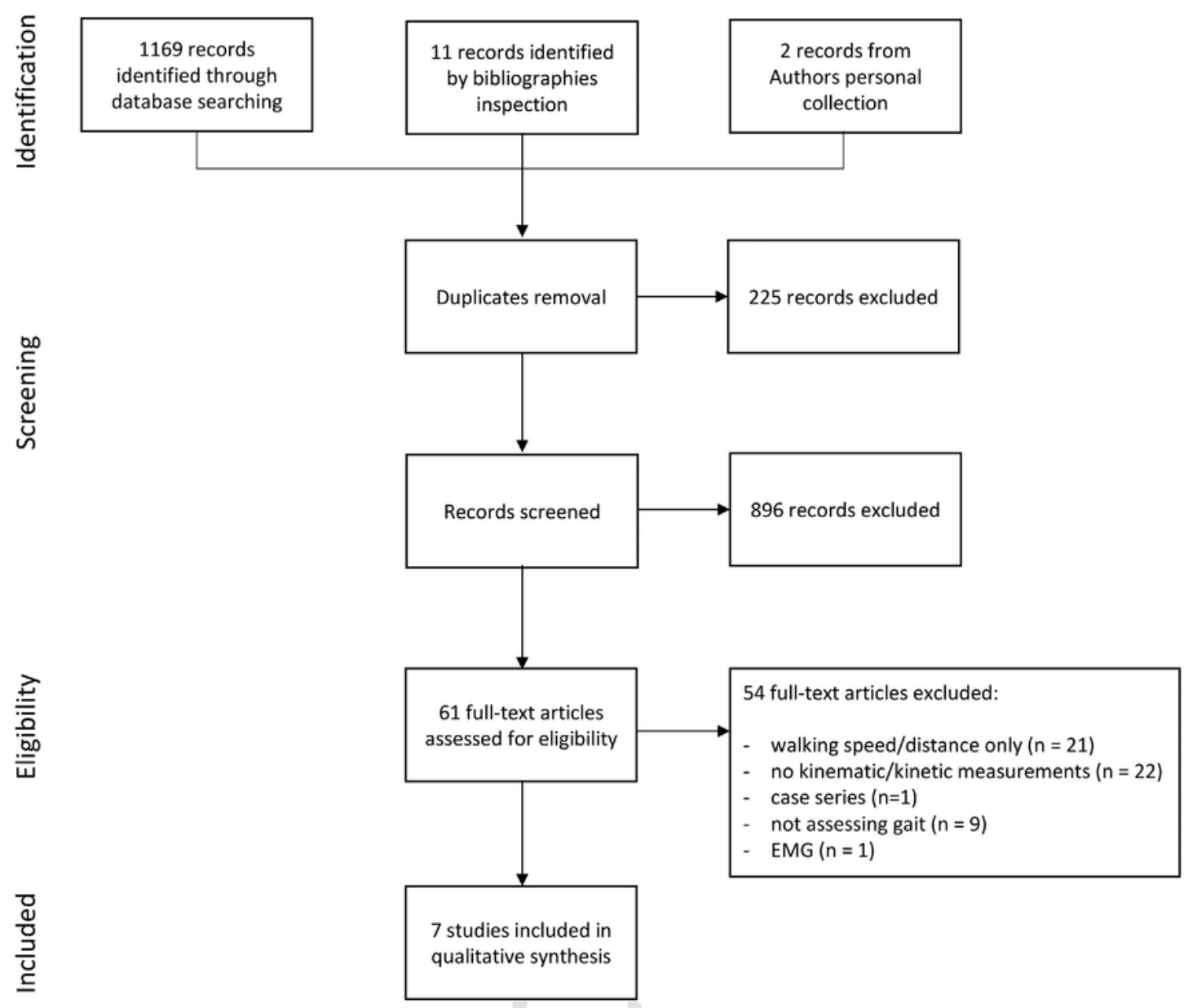

Fig. 1. Articles search process flowchart.

\subsection{Quality of the included studies}

A global picture of the quality of the included studies is reported in Fig. 2. The experimental procedures (flow and timing, tests) were on average fairly good, showing a low risk of bias in $71 \%$ of studies. Conversely, patients' selection was deemed with a high risk of bias in 5 out of 7 studies, with high concerns on the applicability of the results in 2 out of 7 papers. This was mainly due to patients' characteristics: first, the sample size was larger than 20 only in 3 studies. Second, the gender distribution in the COPD groups was not homogeneous and, with few exceptions, unmatched with the control group.

\subsection{Summary of evidence}

The main significant gait differences between patients with COPD and control groups assessed in the reviewed studies are listed in Table 2. Lower walking speed was reported in patients with COPD by Nantsupawat et al. [24]. Yentes et al. [23] noticed a consistent ( $-15 \%)$ whilst not significant ( $\mathrm{p}=0.06, t$-test) reduction in gait speed. McCamley et al. [25] and Yentes et al. [22] did not find significant differences between groups, since they matched patients and controls in terms of walking speed, either a-priori or by covariate analysis. In addition, patients with COPD generally tend to reduce their stride (and step) length and cadence $[12,23,26,27]$.

Variability measures were provided by two papers [23,27]. When evaluated as standard deviation, step width variability was reduced in patients with COPD, and step time variability was increased [23]. A lower autocorrelation coefficient, meaning an increased variability over time, was computed on step width [27].

Only two studies to date presented joint angles and moments curves, and just small abnormalities were reported. While McCamley et al. [25] did not find any significant difference, Yentes et al. [22] observed an altered pattern at the ankle level, after correcting for covariates of age, gender and smoking history. In particular, they measured an increased peak ankle power absorption at mid-stance and a lack of increase in peak ankle dorsiflexion moment in fatigued conditions with respect to controls. Annegarn et al. [27] combined accelerometer data into a unique synthetic variable, called 'walking intensity', that was computed from the integral of the modulus of the output of an accelerometer placed at the trunk level. Walking intensity was lower in COPD patients than in controls, and proved to be strongly correlated with the distance covered in the 6MWT, and moderately correlated with FEV1.

\section{Discussion}

The gait abnormalities that were more frequently identified in patients with COPD were reduced step length and cadence [23,24,26,27], and altered variability of spatiotemporal parameters [23,27]. Subtle biomechanical changes were also reported at the ankle level in terms of joint powers and moments [22]. 
Table 1

Key features of the examined papers. Participants demographics, laboratory equipment, trial specifications and most relevant findings are reported.

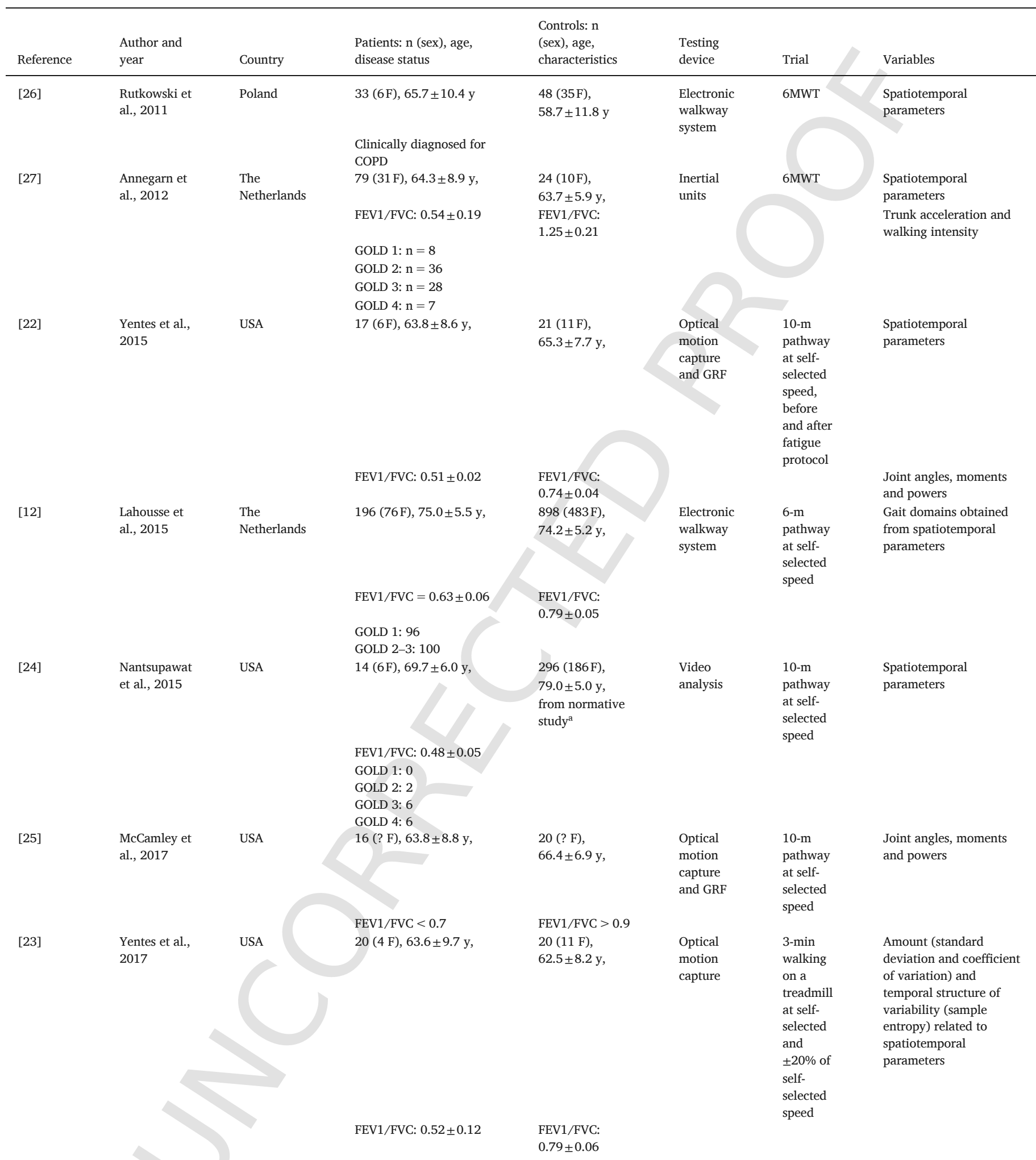

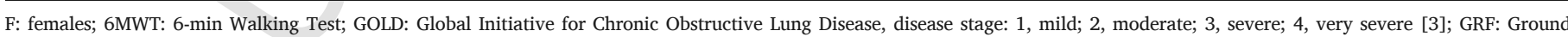
Reaction Force.

a Mayo Clinic Study of Aging [49].

\subsection{Gait characteristics of patients with COPD}

\subsubsection{Spatiotemporal parameters}

There is a general consensus on the fact that patients with COPD walk slower in tests like the 6MWT than healthy age-matched individu- als $[19,28,29]$. However, as speed is responsible of considerable changes in gait patterns [30], to exclude a possible confounding factor and to better identify COPD-specific characteristics, gait should be evaluated at similar speeds as done in [22,25].

A general pattern in patient with COPD is the reduction of stride length and cadence $[12,23,26,27]$. Lahousse et al. revealed that ca- 

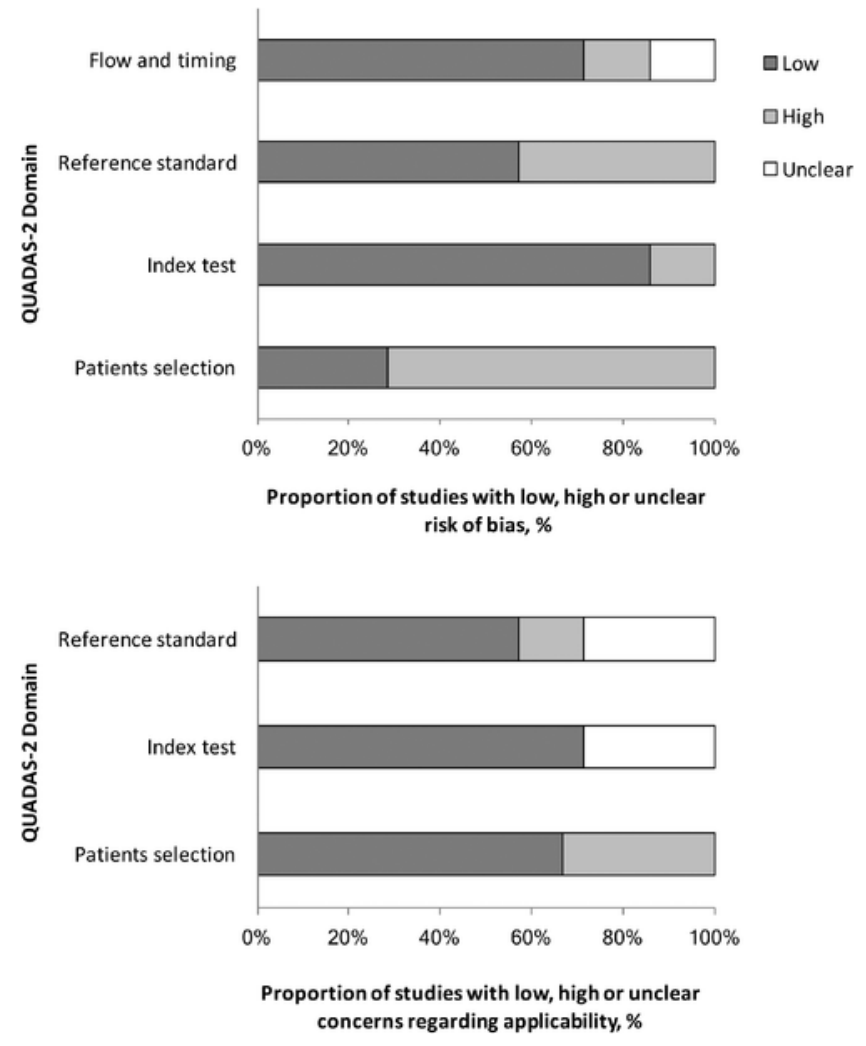

Fig. 2. Summary of the QUADAS-2 results.

dence and speed were positively related with FEV1/FVC, and that their deterioration was associated with the degree of airflow limitation, symptoms and frequency of exacerbations [12]. Abnormalities in stride time were also observed during 6MWT, partially explaining the lower distance covered by patients with COPD in the test [27]. On one hand, increased stride time has been associated to the history of falls: combined with a prolonged double support time [24], it can be a strategy to increase stability and reduce the risk of falls [23,24]. Further, fallers with COPD showed a significantly lower speed and cadence than fallers without COPD [12]. On the other hand, taking slower steps can be the effect of an altered mechanism aimed at coping with impaired walking endurance due to the lack of oxygen supply [12,26]. This might decrease the oxygen requirements of leg muscles and allow for longer walking distance in individuals with impaired lung function [12].

In fatigued conditions, Yentes and collaborators [22] observed that stride length was longer in patients with COPD (possibly due to increased tibialis anterior fatigability), and step width decreased with fatigue instead of increasing as in the healthy controls - the Authors ascribed opposite results obtained from previous observations to a different approach in computing step width [23]. Changes in step width were associated to fall risk [31,32]. Therefore, this pattern could be a sign of instability due to a smaller base of support, and can be explained by a reduced control of balance in the medio-lateral direction due to greater center of pressure and hip angular displacements [7,22,23,33].

\subsubsection{Variability}

Mediolateral variability in gait, largely due to lateral foot placement, was reported as an active control strategy to compensate for balance disturbances and maintain stability in the propulsive (anteroposterior) direction. To compensate for balance disturbances during walking, an adjustment of step width is necessary (largely through lateral foot placement), resulting in an increased variability of the walking
Table 2

significant walking abnormalities identified in the reviewed studies between patients with COPD and healthy controls.

\begin{tabular}{|c|c|c|c|}
\hline Domain & $\begin{array}{l}\text { Qualitative } \\
\text { gait feature } \\
\text { (COPD vs. } \\
\text { controls) }\end{array}$ & $\begin{array}{l}\text { Quantitative } \\
\text { results and } \\
\text { REFERENCES } \\
\text { (COPD vs. } \\
\text { controls) }\end{array}$ & $\begin{array}{l}\text { Rationale and/ } \\
\text { or } \\
\text { consequences }\end{array}$ \\
\hline \multirow[t]{8}{*}{$\begin{array}{l}\text { Spatiotemporal } \\
\text { parameters }\end{array}$} & $\begin{array}{l}\text { Slower } \\
\text { walking } \\
\text { speed }\end{array}$ & $\begin{array}{l}1.09 \mathrm{vs} \text {. } \\
1.17 \mathrm{~m} / \mathrm{s}, \\
\text { outside } 95 \% \\
\text { confidence } \\
\text { interval [24] }\end{array}$ & $\begin{array}{l}\text { Reflects } \\
\text { respiratory } \\
\text { limitations } \\
\text { associated with } \\
\text { muscle wasting, } \\
\text { reduced muscle } \\
\text { strength, } \\
\text { reduced } \\
\text { physical } \\
\text { activity and } \\
\text { loss of } \\
\text { conditioning. }\end{array}$ \\
\hline & $\begin{array}{l}\text { Reduced } \\
\text { step width } \\
\text { (in fatigued } \\
\text { conditions) }\end{array}$ & $\begin{array}{l}0.09 \text { vs } 0.11 \mathrm{~m} \\
\mathrm{p}<0.05\end{array}$ & $\begin{array}{l}\text { Brings to } \\
\text { instability due } \\
\text { to a smaller } \\
\text { base of support. }\end{array}$ \\
\hline & $\begin{array}{l}\text { Increased } \\
\text { step/stride } \\
\text { time or } \\
\text { lower stride } \\
\text { cadence }\end{array}$ & $\begin{array}{l}\text { Stride time, } \\
0.49 \text { vs. } 0.48 \text { s, } \\
p<0.05[26]\end{array}$ & $\begin{array}{l}\text { It is associated } \\
\text { to fall history. }\end{array}$ \\
\hline & & $\begin{array}{l}\text { Encapsulated } \\
\text { in a synthetic } \\
\text { variable } \\
\text { (Rhythm), } \\
\text { p < } 0.05 \text { [12] }\end{array}$ & $\begin{array}{l}\text { Reflects } \\
\text { changes in } \\
\text { performance } \\
\text { capacity. }\end{array}$ \\
\hline & & $\begin{array}{l}\text { Cadence } 0.95 \\
\text { vs. } 1.10 \text { stride/ } \\
\mathrm{s}, \mathrm{p}<0.05 \\
{[27]}\end{array}$ & $\begin{array}{l}\text { Evidence of an } \\
\text { altered walking } \\
\text { pattern. }\end{array}$ \\
\hline & & $\begin{array}{l}\text { Step time } 0.8 \\
\text { vs. } 0.7 \mathrm{~s} \\
\mathrm{p}<0.05\end{array}$ & $\begin{array}{l}\text { Adaptation } \\
\text { mechanism to } \\
\text { cope with } \\
\text { impaired } \\
\text { walking } \\
\text { endurance due } \\
\text { to reduced } \\
\text { oxygen supply. }\end{array}$ \\
\hline & Stride length & $\begin{array}{l}\text { Stride length, } \\
0.75 \text { vs. } 0.77 \mathrm{~m}, \\
\mathrm{p}<0.05[26]\end{array}$ & $\begin{array}{l}\text { Reflects } \\
\text { changes in } \\
\text { performance } \\
\text { capacity } \\
\text { Strategy to } \\
\text { increase } \\
\text { stability and } \\
\text { reduce risk of } \\
\text { fall }\end{array}$ \\
\hline & $\begin{array}{l}\text { Increased } \\
\text { double } \\
\text { support time }\end{array}$ & $\begin{array}{l}0.36 \text { vs. } 0.31 \text {, } \\
\text { outside } 95 \% \\
\text { confidence } \\
\text { interval }[24]\end{array}$ & $\begin{array}{l}\text { Strategy to } \\
\text { increase } \\
\text { stability and } \\
\text { reduce risk of } \\
\text { fall }\end{array}$ \\
\hline \multirow[t]{2}{*}{ Variability } & $\begin{array}{l}\text { Higher step } \\
\text { time SD }\end{array}$ & $\begin{array}{l}0.04 \text { vs. } 0.03 \text { s } \\
\mathrm{p}<0.05\end{array}$ & $\begin{array}{l}\text { Accounts for } \\
\text { the increased } \\
\text { risk of falling in } \\
\text { COPD. }\end{array}$ \\
\hline & $\begin{array}{l}\text { Reduced } \\
\text { step width } \\
\text { SD }\end{array}$ & $\begin{array}{l}0.014 \text { vs. } \\
0.018, p<0.05 \\
{[23]}\end{array}$ & $\begin{array}{l}\text { Accounts for } \\
\text { the increased } \\
\text { risk of falling in } \\
\text { COPD. } \\
\text { Reflects } \\
\text { impaired } \\
\text { balance control } \\
\text { in the } \\
\text { mediolateral } \\
\text { direction. }\end{array}$ \\
\hline
\end{tabular}


Table 2 (Continued)

\begin{tabular}{|c|c|c|c|}
\hline Domain & $\begin{array}{l}\text { Qualitative } \\
\text { gait feature } \\
\text { (COPD vs. } \\
\text { controls) }\end{array}$ & $\begin{array}{l}\text { Quantitative } \\
\text { results and } \\
\text { REFERENCES } \\
\text { (COPD vs. } \\
\text { controls) }\end{array}$ & $\begin{array}{l}\text { Rationale and/ } \\
\text { or } \\
\text { consequences }\end{array}$ \\
\hline \multirow{4}{*}{$\begin{array}{l}\text { Kinematics } \\
\text { and kinetics }\end{array}$} & $\begin{array}{l}\text { Higher } \\
\text { mediolateral } \\
\text { variability }\end{array}$ & $\begin{array}{l}\text { Autocorrelation } \\
\text { coefficient } \\
63.2 \% \text { vs. } \\
73.7 \% \text {, } \\
\text { p }<0.05 \text { [27] }\end{array}$ & $\begin{array}{l}\text { Active control } \\
\text { strategy to } \\
\text { compensate for } \\
\text { balance } \\
\text { disturbances } \\
\text { and maintain } \\
\text { stability in the } \\
\text { anteroposterior } \\
\text { direction. } \\
\text { Reflects higher } \\
\text { balance } \\
\text { disturbances } \\
\text { while walking. }\end{array}$ \\
\hline & $\begin{array}{l}\text { Reduced } \\
\text { walking } \\
\text { intensity }\end{array}$ & $\begin{array}{l}8658 \text { vs. } \\
14,054 \text { counts/ } \\
\min , p<0.05 \\
{[27]}\end{array}$ & $\begin{array}{l}\text { Associated to } \\
6 \mathrm{MWD} \text { results. } \\
\text { Possibility for } \\
\text { routine } \\
\text { assessment of } \\
\text { exercise } \\
\text { performance in } \\
\text { a home-based } \\
\text { setting. }\end{array}$ \\
\hline & $\begin{array}{l}\text { Increase } \\
\text { peak ankle } \\
\text { power } \\
\text { absorption } \\
\text { at mid- } \\
\text { stance }\end{array}$ & $\begin{array}{l}\sim 2 \text { vs. } \sim 1.5 \mathrm{~W} / \\
\mathrm{kg}, \mathrm{p}<0.05 \\
{[22]}\end{array}$ & $\begin{array}{l}\text { Reflects } \\
\text { problems in } \\
\text { controlling the } \\
\text { foot shortly } \\
\text { after heel-strike } \\
\text { (tibialis } \\
\text { anterior } \\
\text { weakness). }\end{array}$ \\
\hline & $\begin{array}{l}\text { Lack of } \\
\text { increase in } \\
\text { peak } \\
\text { dorsiflexion } \\
\text { moment in } \\
\text { fatigued } \\
\text { condition }\end{array}$ & & \\
\hline
\end{tabular}

pattern [27]. Step width variability is the dependent variable associated with fall risk, prediction of falls and fear of falling in older adults, rather than just a mean change in step width [31,34].

In patients with COPD, recent investigations about step width variability reported reductions in both autocorrelation of step width [27], suggesting an increased mediolateral variability, and step width standard deviation [23]. While these may appear as contrasting results, they were in fact complementary. The first (autocorrelation) is about the structure of the movement over time, while the latter (standard deviation) refers to spatiotemporal parameters variability; they both support the idea of a general inability to compensate for instability, thus predisposing an individual to falls [36]. Since both increases and decreases in step width variability are related to a history of falls in older adults $[34,36]$, the assessed contributions were consistent in linking an alteration in walking variability (particularly in the mediolateral direction) to an augmented risk of falling for patients with COPD. Further, walking variability is a clinically relevant variable in these patients, since it significantly contributes to the prediction of the distance in the 6MWT [27].

\subsubsection{Kinematics and kinetics}

A single study observed an increased peak power absorption during midstance measured at the ankle level, together with a lack of increase in peak ankle dorsiflexion moment under fatigued conditions [22]. Combined with the longer stride lengths noted in the same no-rest con- dition, this can be motivated by a problem in controlling the foot shortly after heel-strike due to an early tibialis anterior fatigability [22].

\subsection{Source of gait abnormalities in COPD}

Irregular walking patterns and the decline of physical and ambulatory activity in patients with COPD can be caused by both the chronic respiratory limitations and the systemic comorbidities of the disease. COPD limits ventilation causing dynamic hyperinflation when expiratory time is not sufficient to enable lung emptying $[37,38]$. This imposes constraints on tidal volume, leading to dyspnoea, the most common activity-limiting symptom of COPD. Since the level of dyspnoea is correlated to the intensity of the activity performed, people with COPD tend to progressively reduce their physical activity, even to less than 15-min per day [11].

A systemic inflammation was observed in patients with stable COPD as an increased number of leukocytes, acute phase response proteins (C-reactive proteins and fibrinogen) and cytokines (particularly the tumour necrosis factor (TNF-); the systemic inflammation is involved in the pathogenesis of the majority of systemic effects of COPD [2], including skeletal muscle dysfunction and osteoporosis [3]. Several structural adaptations in muscles develop with COPD, in particular at lower limb level [5]: sarcopenia (loss of muscle cells) and atrophy, decreased capillary and mitochondrial density and a shift from slow-twitch (type-I) towards fast-twitch (type-II) anaerobic muscle fibers, resulting in reduced oxidative and increased glycolytic capacity $[3,13]$. This shift suggests decreased endurance and a higher susceptibility to muscle fatigue and weakness $[4,39,40]$. Interestingly, the fiber shift in patients with COPD is opposite to the shift naturally induced by age [13]. Mechanical unloading due to physical inactivity contributes to peripheral muscle abnormalities and dysfunction. Muscle weakness in COPD has been reported primarily in thigh musculature (quadriceps, in both men and women [41]), and more recently documented in the ankle dorsiflexors and plantarflexors [42,43]. Taken together, these abnormalities indicate an overall decline in both the contractile and oxidative capacity of lower limbs muscles in patients with COPD [11].

Strong correlations exist among fall incidence, sensorimotor postural deficiencies and lower limb muscle weakness. Muscle strength is an essential factor in maintaining postural control and minimizing postural sway, both of which are crucial in preventing older adults from falling [44]. Patients with COPD present a deficit of proprioceptive control and a higher body oscillation frequency [7]. Impaired balance and slower reaction times in response to perturbations increase the risk for falls and important complications, such as fractures $[8,24]$. It was suggested that increased mediolateral body oscillations in patients with COPD may be due to thoracoabdominal asynchrony with inadequate contribution to the thorax compartment to tidal volume that eases postural sway [7].

Gait deficits observed in patients with COPD were similar to those found in patients with an elevated fall risk [6]. The evidence provided in the current review partly supports this line, since gait variability impairments were observed by different Authors [23,27]. The respiratory symptoms and neuromuscular deficits of the disease reduce both function and mobility and would suggest strong changes of the walking function, that in COPD was associated with limp, shuttle or other walking abnormalities [45]. Contrary to this hypothesis, patients with COPD demonstrated minimal significant differences in biomechanical gait analysis, gathered results were not coincident, and there were studies $[22,24,25]$ reporting qualitatively normal gait and balance in similar populations. Thus, the results emerging from the existing literature do not allow to draw conclusive traits of the gait patterns in patients with COPD (Table 2). 


\subsection{Article quality}

The paucity of studies on the topic and the average poor methodological quality in the recruitment of cohorts were the main reasons for the uncertainty and sometimes ambiguity of the results. In particular, four major flaws emerged: small sample size, gender and disease status pooling, speed mismatches.

About sample size, van der Linde et al. [46] suggested that the number of independent variables $(\mathrm{K})$ can be considered adequate if the ratio K:n, where $n$ is the sample size, exceeds $1: 10$. Over $70 \%$ of the articles that we included in the review did not meet such requirement ( $\mathrm{n}=36.8 \pm 18.2$ patients with COPD, range $14-71$, Table 1 ). A small sample size reduces the ability to validate the hypothesis, increases the risk of type-II error and reduces the discriminating capacity of a parameter and in turn the relevance of the results.

The extent to which the disease severity can contribute to mechanical impairments in patients with COPD is still debated. When COPD becomes aggravated, patients suffer from deteriorated functional status and limitations in daily life [28]: physical activity is reduced in patients with GOLD [3] stage 1, and this reduction further worsens with disease severity, being the patients with COPD GOLD stage 4 very inactive [13]. A significant association between COPD severity status and walking and abnormalities was also observed in self-reported reports [45]. This is consistent with the findings by Yentes et al. [22], who noticed larger step width just in COPD GOLD 3 and 4 stages. In sum, deficits in functional balance, coordination, and mobility were associated with disease severity or with differences in activity levels [7,28], and the severe GOLD categories were associated with worse global gait and pace characteristics [27]. Thus, combining data from patients belonging to different stages of the disease could have had the effect of weakening results and masking possible relevant differences between stages of the disease and/or healthy controls. The absence of a clear trend in the reviewed studies can therefore be related to the inherent heterogeneity in which COPD presents itself clinically [22]. Indeed, different phenotypes of the disease have been recently identified based on demographics (age, gender or smoking history), physiological (decline in FEV1/ FVC), radiographic or imaging factors (structural abnormalities), acute exacerbations of COPD, degree of systemic inflammation and the presence of comorbidities (cardiovascular disease, metabolic syndrome, osteoporosis, diabetes, depression) [22,47]. It is possible that a subset of patients with COPD may manifest differences that have not been observed in the larger groups [22].

Gender effect was took into account only by Yentes et al. [22]. Till still debated in the scientific community, in principle one cannot be unaware that sex-specific differences were observed in kinematic and kinetic gait patterns among groups of elderly individuals $[48,49]$. Since such differences concern spatiotemporal parameters (and related variability) that were found to be sensitive to the presence of COPD, comparing severely unbalanced cohorts without correcting for the gender effect might have played an additional role in increasing the sources of bias.

Lastly, walking speed is known to greatly influence gait mechanics [30]. Therefore, results of studies that do not match groups for speed should be regarded with caution. Since a reduced walking velocity is inherently a characteristic of patients with COPD [24], findings could be provided considering speed as a covariate.

\section{Conclusions and recommendations for future research}

This review provided evidence that COPD is likely to alter patients' spatiotemporal gait patterns as compared to healthy age-matched controls. In particular, COPD was related with taking slower steps and with reduced cadence [12,23,24,26,27], increased double support time
[24] and altered gait variability [23,27]. Kinetic abnormalities have been also observed at the ankle level, with a reduction in push-off force following a fatigued condition [22]. However, there is presently a paucity of evidence that identifies a convincing mechanistic link between such gait impairments and falls in patients with COPD.

Overall, due to methodological inconsistencies, the reviewed studies highlighted trends of future investigations rather than crucial differences among the gait patterns of patients with COPD and those of healthy individuals. Two main directions of research emerged: stricter cohorts characterization and longitudinal studies. First, walking abnormalities could be significantly associated with COPD severity [45]. Since all the studies defined COPD by spirometry alone and not by the combination of symptoms and spirometry [3], it is advisable that future researches would investigate biomechanical abnormalities in different COPD phenotypes, distinguishing between disease severity and patients' gender. In that, the heterogeneity of manifestation of COPD in the samples analysed by the current literature is the main limitation that future research is called to fill. Second, future studies might include repeated measures to investigate the effect of a pulmonary rehabilitation program on walking patterns in patients with COPD [27].

Gait instability is a major fall-risk factor in patients with COPD [23], and walking is one of the most frequent dynamic activities of daily living [50]. To allow preventive strategies to become effective, it is crucial to identify individuals with unstable gait. Quantitative gait analysis can reveal abnormal gait parameters that are not apparent to visual inspection or identified by gait speed. The assessment of gait variability provides a viable option for the evaluation of stability and to determine whether mechanical limitations are associated with the severity of the disease $[45,50]$. Lastly, the measurement of joint moments can provide insight into the net response of all muscle groups in the lower limbs, revealing crucial COPD-related adaptations [22]. In turn, this knowledge may aid in identifying proper intervention strategies to prevent falling in patients with COPD [12].

\section{Funding}

This project was supported by an unconditioned Research Grant supplied from the "Filippo Serpero Foundation", Milan, Italy.

\section{Conflict of interest statement}

All authors have no financial and personal relationships with other people or organizations that could inappropriately influence their work. The author confirms that there are no known conflicts of interest regarding the work described in the current manuscript.

\section{Uncited reference}

[35].

\section{References}

[1] D. Adeloye, S. Chua, C. Lee, C. Basquill, A. Papana, E. Theodoratou, H. Nair, D. Gasevic, D. Sridhar, H. Campbell, K.Y. Chan, A. Sheikh, I. Rudan, Global and regional estimates of COPD prevalence: systematic review and meta-analysis, J. Glob. Health 5 (2015).

[2] A. Agusti, A. Agustí, Systemic effects of chronic obstructive pulmonary disease: what we know and what we don't know (but should), Proc. Am. Thorac. Soc. 4 (2007) 522-525.

[3] C.F. Vogelmeier, G.J. Criner, F.J. Martinez, A. Anzueto, P.J. Barnes, J. Bourbeau, B.R. Celli, R. Chen, M. Decramer, L.M. Fabbri, P. Frith, D.M.G. Halpin, M.V. López Varela, M. Nishimura, N. Roche, R. Rodriguez-Roisin, D.D. Sin, D. Singh, R. Stockley, J. Vestbo, J.A. Wedzicha, A. Agustí, Global strategy for the diagnosis management, and prevention of chronic obstructive lung disease 2017 report. GOLD executive summary, Am. J. Respir. Crit. Care Med. 195 (2017) 557-582.

[4] Y. Nussbaumer-Ochsner, K.F. Rabe, Systemic manifestations of COPD, Chest 139 (2011) 165-173. 
[5] S. Bernard, P. LeBlanc, F. Whittom, G. Carrier, J. Jobin, R. Belleau, F. Maltais, Peripheral muscle weakness in patients with chronic obstructive pulmonary disease, Am. J. Respir. Crit. Care Med. 158 (1998) 629-634.

[6] M.K. Beauchamp, D. Brooks, R.S. Goldstein, Deficits in postural control in individuals with COPD - emerging evidence for an important secondary impairment, Multidiscip. Respir. Med. 5 (2010) 417-421.

[7] E.F. Porto, A.A.M. Castro, V.G.S. Schmidt, H.M. Rabelo, C. Kumpel, O.A. Nascimento, J.R. Jardim, Postural control in chronic obstructive pulmonary disease: a systematic review, Int. J. Chron. Obstruct. Pulmon. Dis. 10 (2015) 1233-1239.

[8] M. Roig, J.J. Eng, D.L. MacIntyre, J.D. Road, W.D. Reid, Deficits in muscle strength mass, quality, and mobility in people with chronic obstructive pulmonary disease, J. Cardiopulm. Rehabil. Prev. 31 (2010) 120-124.

[9] S.J. Butcher, J.M. Meshke, M.S. Sheppard, Reductions in functional balance, coordination, and mobility measures among patients with stable chronic obstructive pulmonary disease, J. Cardiopulm. Rehabil. 24 (2004) 274-280.

[10] M.D. Eisner, P.D. Blanc, E.H. Yelin, S. Sidney, P.P. Katz, L. Ackerson, P. Lathon, I. Tolstykh, T. Omachi, N. Byl, C. Iribarren, COPD as a systemic disease: impact on physical functional limitations, Am. J. Med. 121 (2008) 789-796.

[11] M. Roig, J.J. Eng, J.D. Road, W.D. Reid, Falls in patients with chronic obstructive pulmonary disease: a call for further research, Respir. Med. 103 (2009) 1257-1269.

[12] L. Lahousse, V.J.A. Verlinden, J.N. Van Der Geest, G.F. Joos, A. Hofman, B.H.C. Stricker, G.G. Brusselle, M.A. Ikram, J.N. Van Der Geest, G.F. Joos, A. Hofman, B.H.C. Stricker, G.G. Brusselle, M.A. Ikram, Gait patterns in COPD: the Rotterdam study, Eur. Respir. J. 46 (2015) 88-95.

[13] N. Cielen, K. Maes, G. Gayan-Ramirez, Musculoskeletal disorders in chronic obstructive pulmonary disease, Biomed Res. Int. 2014 (2014).

[14] P. Kannus, H. Sievänen, M. Palvanen, T. Järvinen, J. Parkkari, Prevention of falls and consequent injuries in elderly people, Lancet 366 (2005) 1885-1893.

[15] A. Clegg, J. Young, S. Iliffe, M.O. Rikkert, K. Rockwood, Frailty in elderly people, Lancet 381 (2013) 752-762.

[16] S.A. Bridenbaugh, R.W. Kressig, Laboratory review: the role of gait analysis in seniors' mobility and fall prevention, Gerontology 57 (2011) 256-264.

[17] J. Verghese, R. Holtzer, R.B. Lipton, C. Wang, Quantitative gait markers and incident fall risk in older adults, J. Gerontol. Ser. A Biol. Sci. Med. Sci. 64 (2009) 896-901.

[18] T. Ringbaek, G. Martinez, E. Brøndum, J. Thøgersen, M. Morgan, P. Lange, Shuttle walking test as predictor of survival in chronic obstructive pulmonary disease patients enrolled in a rehabilitation program, J. Cardiopulm. Rehabil. Prev. 30 (2010) 409-414.

[19] C. Karpman, R. Benzo, Gait speed as a measure of functional status in COPD patients, Int. J. COPD 9 (2014) 1315-1320.

[20] C. Garvey, A.M. Boylan, D.L. Miller, A.E. Holland, S.J. Singh, M.A. Spruit, K.C. Wilson, C.C. Thomson, Field walking tests in chronic respiratory disease, Ann. Am. Thorac. Soc. 12 (2015) 446-447.

[21] P. Whiting, A. Rutjes, M. Westwood, S. Mallett, J. Deeks, J. Reitsma, M.M. Leeflang, J.A. Sterne, P. Bossuyt, QUADAS-2: a revised tool for the quality assessment of diagnostic accuracy studies, Ann. Intern. Med. 155 (2011) 529-536.

[22] J.M. Yentes, K.K. Schmid, D. Blanke, D.J. Romberger, S.I. Rennard, N. Stergiou, Gait mechanics in patients with chronic obstructive pulmonary disease, Respir. Res. 16 (2015) 31.

[23] J.M. Yentes, S.I. Rennard, K.K. Schmid, D. Blanke, N. Stergiou, Patients with COPD walk with altered step time and step width variability as compared to healthy controls, Ann. Am. Thorac. Soc. (2017), AnnalsATS.201607-547OC.

[24] N. Nantsupawat, P. Lane, O. Siangpraipunt, S. Gadwala, K. Nugent, Gait characteristics in patients with chronic obstructive pulmonary disease, J. Prim. Care Community Health 6 (2015) 222-226.

[25] J.D. McCamley, E.J. Pisciotta, J.M. Yentes, S.R. Wurdeman, S.I. Rennard, I.I. Pipinos, J.M. Johanning, S.A. Myers, Gait deficiencies associated with peripheral artery disease are different than chronic obstructive pulmonary disease, Gait Posture 57 (2017) 258-264.

[26] S. Rutkowski, A. Rutkowska, J. Łuniewski, J. Szczegielniak, Gait analysis of patients with chronic obstructive pulmonary disease, Fizjoterapia Pol. 4 (2011) 24-33.

[27] J. Annegarn, M.A. Spruit, H.H.C.M. Savelberg, P.J.B. Willems, C. van de Bool, A.M.W.J. Schols, E.F.M. Wouters, K. Meijer, C. Van De Bool, A.M.W.J. Schols,
E.F.M. Wouters, K. Meijer, Differences in walking pattern during 6-min walk test between patients with COPD and healthy subjects, PLoS One 7 (2012) 3-8.

[28] Y. Liu, H. Li, N. Ding, N. Wang, D. Wen, Functional status assessment of patients with COPD, Medicine (Baltimore) 95 (2016) e3672.

[29] C. Karpman, Z.S. Depew, N.K. Lebrasseur, P.J. Novotny, R.P. Benzo, Determinants of gait speed in COPD, Chest 146 (2014) 104-110.

[30] J. Perry, J.M. Burnfield, Gait Analysis: Normal and Pathological Function, 2nd ed., SLACK Incorporated, Thorofare, New Jersey, 2010

[31] J.C. Dean, N.B. Alexander, A.D. Kuo, The effect of lateral stabilization on walking in young and old adults, IEEE Trans. Biomed. Eng. 54 (2007) 1919-1926.

[32] M.A. Schrager, V.E. Kelly, R. Price, L. Ferrucci, A. Shumway-Cook, The effects of age on medio-lateral stability during normal and narrow base walking, Gait Posture 28 (2008) 466-471.

[33] M.D. Smith, A.T. Chang, H.E. Seale, J.R. Walsh, P.W. Hodges, Balance is impaired in people with chronic obstructive pulmonary disease, Gait Posture 31 (2010) 456-460.

[34] J.S. Brach, J.E. Berlin, J.M. VanSwearingen, A.B. Newman, S. a Studenski, Too much or too little step width variability is associated with a fall history in older persons who walk at or near normal gait speed, J. Neuroeng. Rehabil. 2 (2005) 21.

[35] J.M. Yentes, S.I. Rennard, K.K. Schmid, D. Blanke, N. Stergiou, Patients with chronic obstructive pulmonary disease walk with altered step time and step width variability as compared with healthy control subjects, Ann. Am. Thorac. Soc. 14 (2017) 858-866.

[36] O. Beauchet, G. Allali, C. Annweiler, S. Bridenbaugh, F. Assal, R.W. Kressig, F.R. Herrmann, Gait variability among healthy adults: low and high stride-to-stride variability are both a reflection of gait stability, Gerontology55 (2009) 702-706.

[37] D.E. O'Donnell, J. Ora, K.A. Webb, P. Laveneziana, D. Jensen, Mechanisms of activity-related dyspnea in pulmonary diseases, Respir. Physiol. Neurobiol. 167 (2009) 116-132.

[38] N.R. MacIntyre, Mechanisms of functional loss in patients with chronic lung disease, Respir. Care 53 (2008) 1177-1184.

[39] H.R. Gosker, H. van Mameren, P.J. van Dijk, M.P.K.J. Engelen, G.J. van der Vusse, E.F.M. Wouters, A.M.W.J. Schols, Skeletal muscle fibre-type shifting and metabolic profile in patients with chronic obstructive pulmonary disease, Eur. Respir. J. 19 (2002) 617-625.

[40] M.J. Mador, O. Deniz, A. Aggarwal, T.J. Kufel, Quadriceps fatigability after single muscle exercise in patients with chronic obstructive pulmonary disease, Am. J. Respir. Crit. Care Med. 168 (2003) 102-108.

[41] H.R. Gosker, M.K. Hesselink, H. Duimel, K.A. Ward, A.M. Schols, Reduced mitochondrial density in the vastus lateralis muscle of patients with COPD, Eur. Respir. J. 30 (2007) 73-79.

[42] P. Gagnon, F. Maltais, L. Bouyer, F. Ribeiro, V. Coats, C. Brouillard, M. Noël, M. Rousseau-Gagnon, D. Saey, Distal leg muscle function in patients with COPD, COPD 10 (2013) 235-242.

[43] M. Maddocks, M. Jones, T. Snell, B. Connolly, S. de Wolf-Linder, J. Moxham, G.F. Rafferty, Ankle dorsiflexor muscle size, composition and force with ageing and chronic obstructive pulmonary disease, Exp. Physiol. 99 (2014) 1078-1088.

[44] J.D. Moreland, J.A. Richardson, C.H. Goldsmith, C.M. Clase, Muscle weakness and falls in older adults: a systematic review and meta-analysis, J. Am. Geriatr. Soc. 52 (2004) 1121-1129.

[45] J.M. Yentes, H. Sayles, J. Meza, D.M. Mannino, S.I. Rennard, N. Stergiou, Walking abnormalities are associated with COPD: an investigation of the NHANES III dataset, Respir. Med. 105 (2011) 80-87.

[46] H. van der Linde, C.J. Hofstad, A.C.H. Geurts, K. Postema, J.H.B. Geertzen, J. van Limbeek, A systematic literature review of the effect of different prosthetic components on human functioning with a lower-limb prosthesis, J. Rehabil. Res. Dev. 41 (2004) 555-570.

[47] X. Chen, X. Xu, F. Xiao, Heterogeneity of chronic obstructive pulmonary disease: from phenotype to genotype, Front. Med. 7 (2013) 425-432.

[48] S. Ko, M.I. Tolea, J.M. Hausdorff, L. Ferrucci, Sex-specific differences in gait patterns of healthy older adults: results from the Baltimore longitudinal study of aging, J. Biomech. 44 (2011) 1974-1979.

[49] J.H. Hollman, E.M. McDade, R.C. Petersen, Normative spatiotemporal gait parameters in older adults, Gait Posture 34 (2011) 111-118.

[50] D. Hamacher, N.B. Singh, J.H. Van Dieen, M.O. Heller, W.R. Taylor, Kinematic measures for assessing gait stability in elderly individuals: a systematic review, $\mathrm{J}$. R. Soc. Interface 8 (2011) 1682-1698. 